\title{
Determinants of technical efficiency in the bioenergy industry in the EU28 region
}

\begin{abstract}
Most previous bioenergy industry research has concentrated on how to implement a certain level of yield. However, few articles have paid attention to rational resource allocation to increase efficiency. To enhance bioenergy production through proper use of available resources, this study identified the effects of internal (country-specific) and external (macroeconomic) determinants of technical efficiency level in the bioenergy industry for the EU28 region. The study was established based on a conceptual framework suggesting a correlation between input use and level of technical efficiency. A panel data analysis method was employed for the analysis and a panel regression analysis framework based on the Fixed Effect (FE) model and Random Effect (RE) model was used to examine the potential determinants of technical efficiency level in the bioenergy industry for the EU28 region for the period between 1990 and 2013. The results indicate that the technical efficiency level of the bioenergy industry in developing countries is higher than in developed countries. The empirical findings also suggest that technical efficiency has greater influence on pure technical efficiency levels. Capital input, labor input, gross domestic product, inflation and interest rate significantly affected the technical efficiency of the bioenergy industry in the developing and developed countries in the EU28 region during the period of this study. The findings clearly call for regulators and decision makers to review the technical efficiency level of the bioenergy industry within the EU28 region. This study also provides better information and guidance to the boards of the bioenergy industry, as they need to have a clear understanding of the influence technical efficiency has on bioenergy production performance. Moreover, the results of this study have implications for investors who focus mainly on profits from their investments.
\end{abstract}

Keyword: Bioenergy industry; Technical efficiency; EU28 region 